\title{
Isolation and culture of dental pulp stem cells from permanent and deciduous teeth
}

\author{
Shagufta Naz', Farhan Raza Khan², Raheela Rahmat Zohra \\ Sahreena Salim Lakhundi ${ }^{4}$, Mehwish Sagheer Khan ${ }^{5}$, \\ Nuruddin Mohammed ${ }^{6}$, Tashfeen Ahmad
}

\section{ABSTRACT}

Objective: To isolate dental pulp mesenchymal stem cells (MSCs) from non-infected human permanent and deciduous teeth.

Methods: It was an in-vitro experimental study. Human teeth were collected from 13 apparently healthy subjects including nine adults and four children. After decoronation dental pulps were extirpated from teeth and cultured via explant method in a stem cell defined media. Data was analyzed by descriptive statistics.

Results: As above MSCs emerged exhibiting fibroblast-like morphology. In vitro culture was positive for $100 \%$ $(9 / 9)$ and $75 \%(3 / 4)$ of the permanent and deciduous teeth respectively. First cell appeared from deciduous teeth pulp in $10 \pm 6.2$ days while permanent teeth pulp took $12.4 \pm 3.7$ days. Together, $26.6 \pm 3.6$ and $24.5 \pm 3.5$ days were required for permanent and deciduous tooth pulp stem cells to be ready for further assays.

Conclusions: The protocol we developed is easy and consistent and can be used to generate reliable source of MScs for engineering of calcified and non-calcified tissue for regenerative medicine approaches.

KEYWORDS: Dental pulp, Tissue explant, Mesenchymal stem cells, Permanent teeth, Primary / Deciduous teeth, Tissue engineering.

doi: https://doi.org/10.12669/pjms.35.4.540

How to cite this:

Naz S, Khan FR, Zohra RR, Lakhundi SS, Khan MS, Mohammed N, et al. Isolation and culture of dental pulp stem cells from permanent and deciduous teeth. Pak J Med Sci. 2019;35(4):997-1002. doi: https://doi.org/10.12669/pjms.35.4.540

This is an Open Access article distributed under the terms of the Creative Commons Attribution License (http://creativecommons.org/licenses/by/3.0), which permits unrestricted use, distribution, and reproduction in any medium, provided the original work is properly cited.

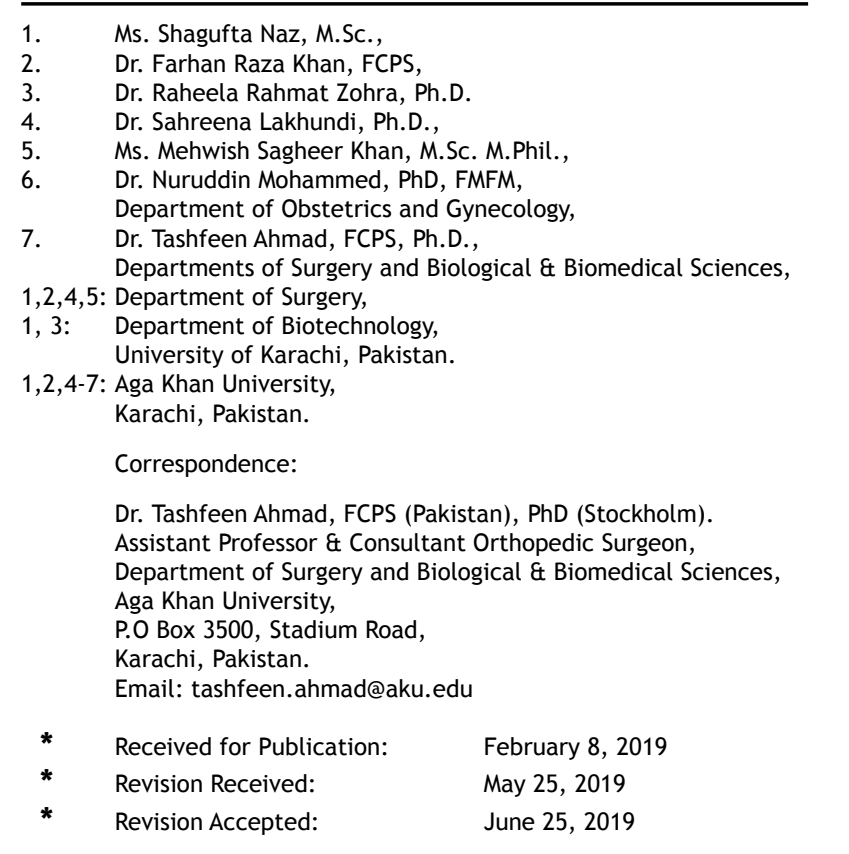

\section{INTRODUCTION}

Mesenchymal stem cells (MSCs) are attractive tools for tissue repair because of their differentiation capability and abundance in tissues. ${ }^{1}$ Virtually every tissue has tissue specific stem cells. ${ }^{2}$ Although, MSCs were first isolated in bone marrow, ${ }^{3}$ a decline is observed in using bone marrow MSCs while interestingly, an increasing trend is evident regarding exploration of various postnatal tissues as a source of MSCs. ${ }^{4}$ Growing evidence suggests a remarkable regenerative potential of MSCs from dental derived tissue such as Dental pulp stem cells (DPSCs) from impacted third molar, ${ }^{5}$ stem cells from apical papilla (SCAP) ${ }^{6}$ and stem cells from human exfoliated deciduous teeth (SHED). ${ }^{7}$

Permanent and deciduous (primary) teeth are considered as an easily accessible source for isolation and subsequent expansion of dental pulp cells for 
the purposes of tissue engineering. The collection of dental pulp is an easier and safer undertaking than the collection from bone marrow. ${ }^{8}$

Since the discovery of dental pulp stem cells in 2000, these have been investigated extensively through invitro and in-vivo approaches. Very recently, researchers in Japan have conducted a phase I clinical trial to evaluate the safety of autologous dental pulp stem cells for regenerating dental pulp (DP). ${ }^{9}$

In Pakistan, the potential of dental pulp stem cells has yet to be explored in pre-clinical and clinical trials. Therefore, in the present study, we aim to develop a protocol for the isolation and culture of dental pulp stem cells from permanent and deciduous teeth with a long term goal of their use in regenerative medicine applications.

\section{METHODS}

Recruitment and Collection of Teeth Samples: This was an in vitro study on human samples. Patients were recruited from dental clinics at Aga Khan University Hospital, Karachi. Inclusion criteria for permanent teeth selection were healthy adult subjects; aged between 18 to 85 years, presenting for extraction of un-diseased third molars or orthodontic patients needing extraction of sound premolars for braces treatment. The inclusion criteria for deciduous teeth were healthy children; aged between 9 to 12 years, presenting with teeth near to physiologic tooth exfoliation. Only those deciduous teeth were selected whose dental pulp was sound and without any carious exposure. Written informed consent was obtained from adult subjects and assents from parents of children in English, or their native language. The study was approved by institutional Ethics Review Committee (ERC), Ref number 4-1997-BBS-ERC-12. The exodontia of teeth was performed under local anesthesia in all subjects except two. One adult subject underwent tooth extraction under general anesthesia and one child subject shed off tooth by gentle manipulation without any need for local anesthesia.

Sample Processing: A total of nine $(\mathrm{n}=9)$ permanent and four $(n=4)$ deciduous teeth were collected. After disinfecting with 3\% sodium hypochlorite solution for two minutes, tooth was rinsed with $1 X$ phosphate buffer saline (PBS) and dried using cotton gauze. A cut around the cemento-enamel junction was made using a sterilized dental diamond fissure burs (Mani, Inc. USA) along with high speed hand piece (NSK, USA) under copious water supply to decoronate the tooth to expose the pulp chamber as shown in Fig.1A \& 1B.

Sectioned teeth were placed into the transport media (TM) containing basic medium Dulbecco modified essential medium F12 (DMEM-F12) supplemented with $20 \%$ fetal bovine serum (FBS) and penicillin $500 \mathrm{U} / \mathrm{mL}$, streptomycin $500 \mu \mathrm{g} / \mathrm{mL}$, amphotericin B $1.25 \mu \mathrm{g} / \mathrm{mL}$ ) (Sigma Aldrich, Merck, USA). Samples then placed on ice were transferred to Juma Research Laboratories at Aga Khan University Hospital for subsequent processing and culture. Using aseptic condition, $100 \mathrm{~mm}$ petri plate (Sterilin) were set up for processing of each tooth in a biohazard laminar flow hood. Extracted tooth was decanted in a petri plate. Tooth was hold with the help of a sterile forceps and gently extirpated out DP tissue using endodontic H-file \# 30 (MANI, Inc, USA). DP tissue was placed in 1X PBS containing $1 \%$ antibiotic antimycotic solution (Sigma Aldrich) in a petri plate for 10 to 20 minutes as seen in Fig. 2A and was washed twice with 1X PBS (Sigma Aldrich, Merck, USA) each for 10 minutes. Then were transferred into a new petri plate containing DMEM-F12 with $20 \%$ FBS. Minced into $1-2 \mathrm{~mm}^{3}$ pieces using surgical blade \# 20 (Feather, WAPI, USA) as demon-

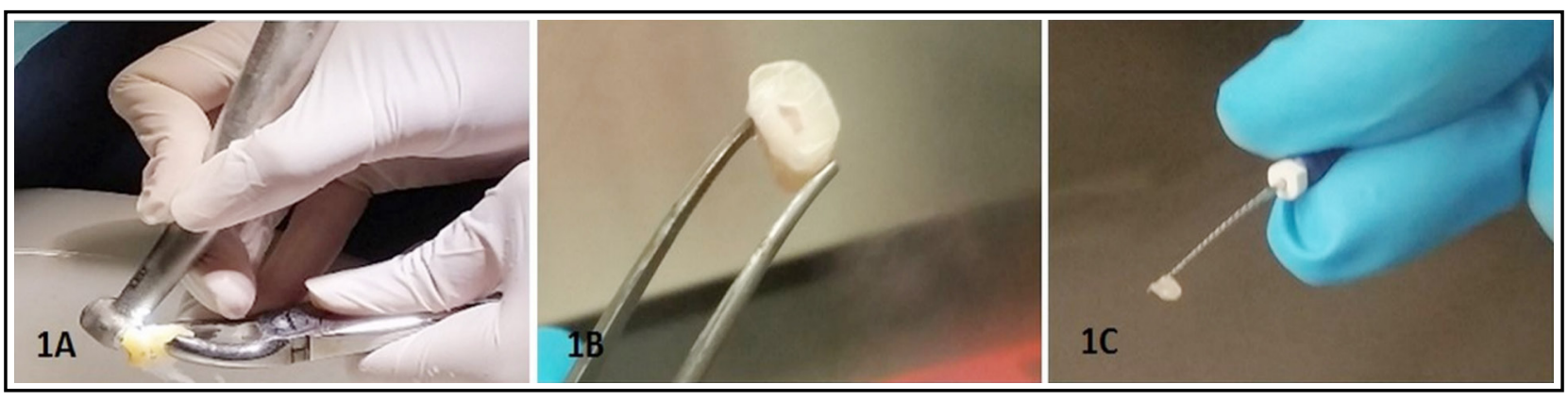

Fig.1: Collection of dental pulp tissue from extracted tooth. (1A) Cutting procedure of extracted tooth after disinfection; with the help of a stable finger support using dental fissure burs, the tooth was decoronated till cemento-enamel junction.

Decoronation is an exothermic process therefore, an ample amount of sterile water was sprayed to reduce the heat.

(1B) Removal of crown exposed the pulp chamber. (1C) Extirpated dental pulp from adult tooth on the tip of dental file. 


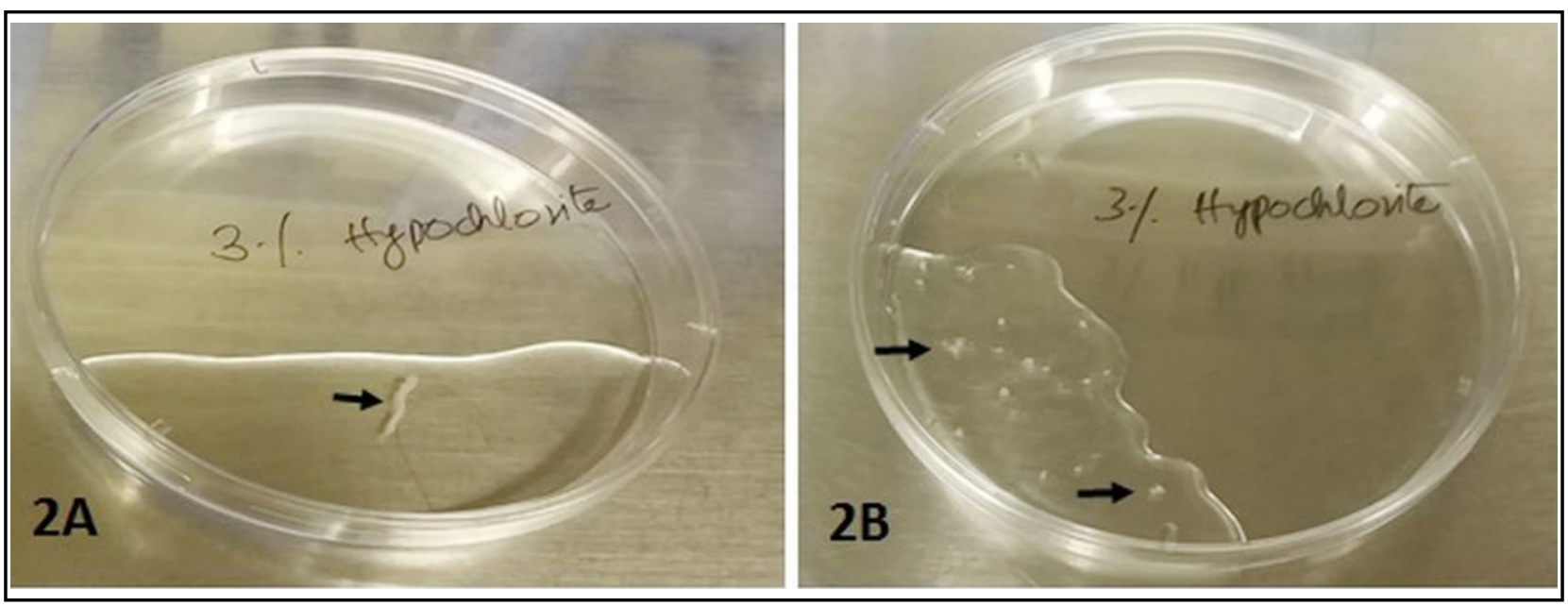

Fig.2: Dental pulp tissue in 1X PBS before (2A) and after (2B) mechanical mincing (arrows).

strated in Fig.2B. DP minced fragments were plated in a T-25 flask (Thermo Scientific, USA) containing DMEM-F12 supplemented with 20\% FBS, penicillin $100 \mathrm{U} / \mathrm{mL}$, streptomycin $100 \mu \mathrm{g} / \mathrm{mL}$, amphotericin B $0.25 \mu \mathrm{g} / \mathrm{mL}, 1 \mathrm{mM}$ sodium pyruvate and $2 \mathrm{mM}$ L-glutamine (Sigma Aldrich). Explants were cultured at $37^{\circ} \mathrm{C}$ in a humidified incubator with $5 \%$ $\mathrm{CO}_{2}$. Cultures were observed daily under inverted microscope (Olympus Corp, USA) for any contamination and cell growth via migration from explant. Micrographs were captured using DSL3 standalone microscope camera controller (Nikon, Japan) at different magnifications.

Passage: When cells reached 70 to $80 \%$ confluency they were either used for an assay or cryopreserved for later use. Cells were thoroughly washed with 1X PBS twice, tryspinized with $0.05 \%$ Trypsin-EDTA (Sigma Aldrich) for two to five minutes, neutralized by adding $10 \%$ FBS containing DMEM-F12. Detached cells were transferred in a tube, centrifuged at $500 \mathrm{~g}$ for five minutes. Carefully decanted the supernatant, make sure not to dislodge the cell pellet. Cells were resuspended either in growth media for an intended assay or stored using freezing media containing 90\% FBS and 10\% DMSO (Sigma Aldrich) in liquid nitrogen at $-196^{\circ} \mathrm{C}$ for later use or long term storage.
Viability Assay: Cells were grown till reached 60$65 \%$ confluency. Briefly, cells were tryspinized and resuspended in complete media. Equal volumes of cell suspension and $0.4 \%$ trypan blue (Gibco) were mixed, $10 \mu \mathrm{L}$ of prepared sample were loaded in both chamber of hemocytometer. Viable and nonviable cells were counted within five minutes of preparing sample. ${ }^{10}$ Counting was performed in duplicate.

Statistical Analysis: Data was analyzed using mean \pm SD.

\section{RESULTS}

DP tissues were extirpated from tooth by decoronation as shown in Fig.1C and were cultured via outgrowth / tissue explant method. In terms of cellular morphology, cells migrated out of the tissue explant, exhibited homogenous morphology having a typical fibroblast-like shape, with long cytoplasmic processes as shown in Fig.3A \& 3B.

The in vitro explant culture was positive for $100 \%$ $(9 / 9)$ and $75 \%(3 / 4)$ permanent and deciduous teeth respectively. One pulp tissue from deciduous teeth didn't show cell grow at all. The reason might be the osmotic shock to the pulp tissue due to sample transportation without transport media. The other pulp tissue grew into small colonies however, got contaminated during long primary culture. Both

Table-I: Tabular summary of isolation and culture of dental pulp stem cells derived from permanent and deciduous teeth.

\begin{tabular}{lcccc}
\hline Type of Teeth & In-vitro Culture & $\begin{array}{c}\text { First Cell } \\
\text { Appearance (days) }\end{array}$ & $\begin{array}{c}\text { Sub-culture } \\
\text { (days) }\end{array}$ & $\begin{array}{c}\text { Primary culture } \\
\text { Duration (days) }\end{array}$ \\
\hline Permanent $(\mathrm{n}=9)$ & Positive $(100 \%)$ & $12.4 \pm 3.7$ & $13.9 \pm 4.2$ & $26.6 \pm 3.6$ \\
Primary $(\mathrm{n}=4)$ & Positive $(75 \%)$ & $10 \pm 6.2$ & $13.5 \pm 4.9$ & $24.5 \pm 3.5$ \\
\hline
\end{tabular}




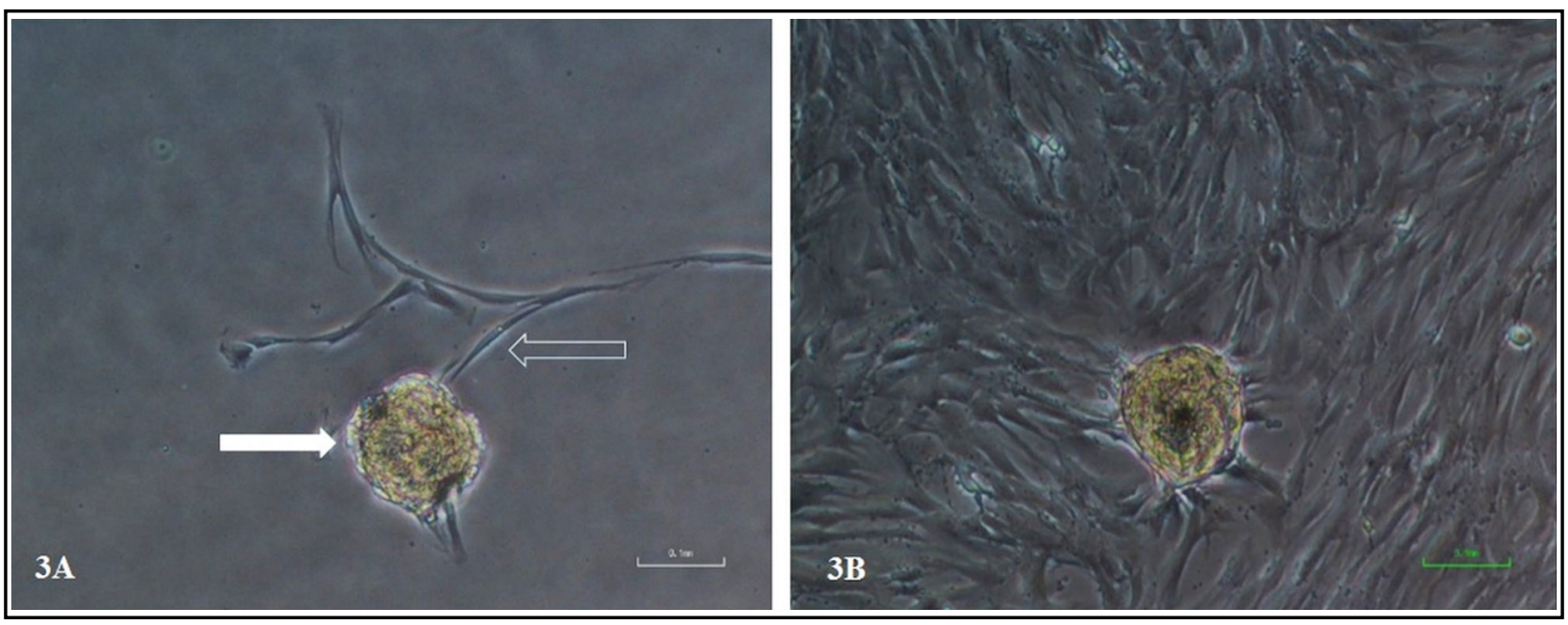

Fig.3: Dental pulp stem cells emerging from tissue explant. (3A) The micrograph showed the dental pulp tissue explant (solid arrow) and newly emerging cells from tissue explant (hollow arrow) at day 11 of culture. The cells exhibit typical morphology of fibroblast like cells with long cytoplasmic extension. (3B) showed same tissue explant after 19 days of culture with confluent field of view. Magnification 100X.

cell type exhibited low proliferative potential. DPSCs and SHED slightly differ in their growth rate. Deciduous teeth pulp gave rise first cell in 10 \pm 6.2 days of culture while pulp from permanent teeth took $12.4 \pm 3.7$ days for the emergence of first cells. Together, $26.6 \pm 3.6$ and $24.5 \pm 3.5$ days were required for DPSC and SHED to be ready for further assays Table-I. Two pulp tissues, derived from a permanent and a deciduous tooth, were subjected to delayed processing of 21 and 24 hours respectively. In contrast to an average of $10 \pm 6.2$ days, the first cell appeared from deciduous teeth pulp tissue was increased to 17 days. However, the change due to delay in processing was not significant in case of pulp from permanent teeth.

Cellular viability of DPSC and SHED was observed using trypan blue dye exclusion test indicating the cell membrane integrity was preserved during cryopreservation as shown in Fig.4. We found $99.4 \pm .09 \%$ and $94.19 \pm 1.65 \%$ viability for DPSC and SHED respectively.

\section{DISCUSSION}

We report a protocol that describes the isolation and culture of human dental pulp mesenchymal stem cells from permanent and deciduous teeth
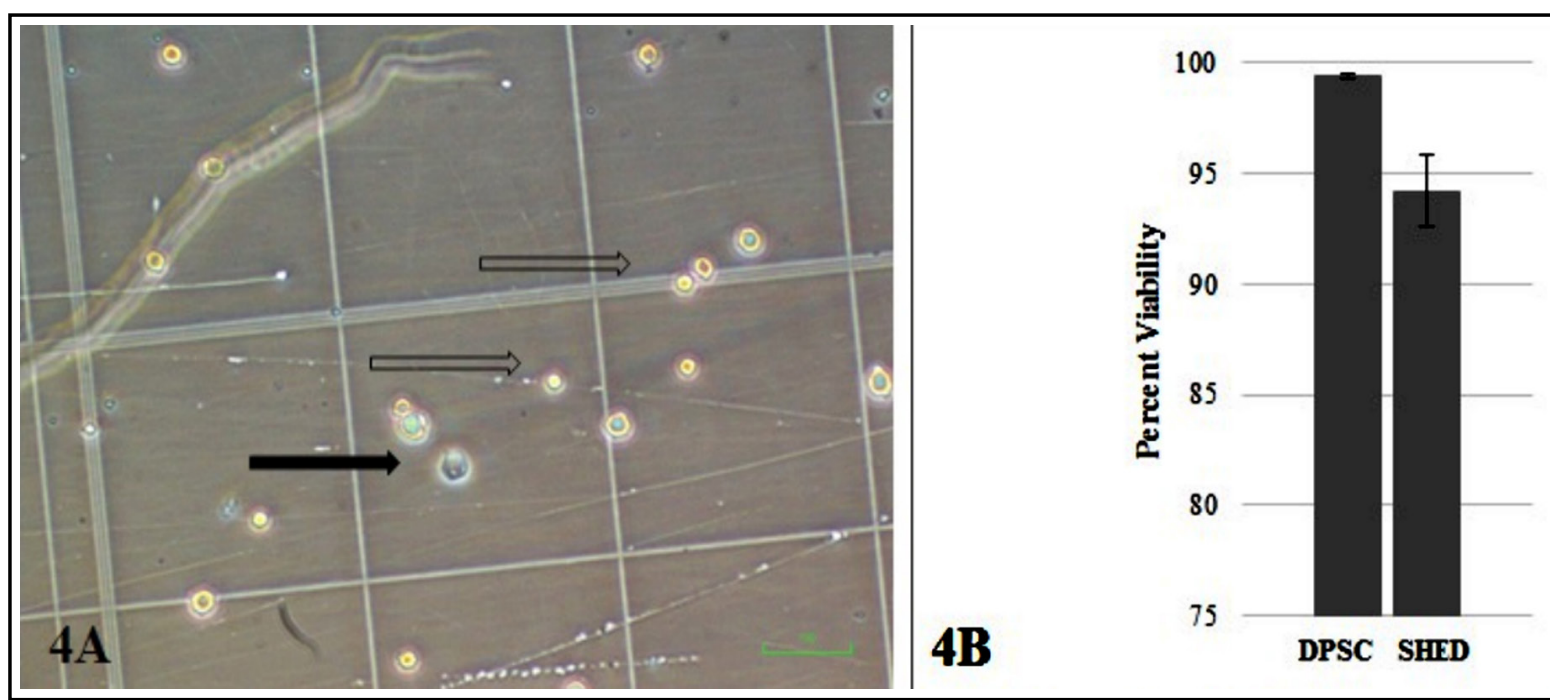

Fig.4: Trypan blue dye exclusion test showed that dental pulp MSCs remain viable after cryopreservation. (4A) hemocytometer counting chamber viable (hollow arrow) and non viable cell (solid arrow).

(4B) percent viability of DPSC and SHED after cryopreservation. Error bar indicates standard deviation. 
using explant method. DPSCs obtained from enzymatic and explant methods were reported to be comparable in terms of mesenchymal stem cell marker expression and multi-lineage differentiation thus suggested to be used as suitable autologous source to regenerate bone and cartilage. ${ }^{11}$

The emerging cells from tissue explant form loose colonies, comprised of cells with characteristic spindle shaped morphology, unlike epithelial cells which forms compact colonies. Our data are consistent with the results of other studies in which a homogenous population of cells were observed using tissue explant method. ${ }^{12,13}$ Interestingly, the protocol we developed is equally useful for teeth samples stored for up to 24 hours at $4^{\circ} \mathrm{C}$. This is especially important, where a delay in sample processing is unavoidable. We presume such a strategy may be employed in setting up a tooth bank as reported elsewhere. ${ }^{14}$

The explant method has been extensively used for studying the dental pulp cells physiology, cell subpopulations capable of differentiating into odontoblasts or mineral-forming cells in vitro ${ }^{15}$ and dentin-like structure in vitro. ${ }^{16}$ DPSCs and SHED obtained from enzyme digestion were also capable of differentiating into odontoblast-like cells and produced dentin in vivo., ${ }^{6,7}$ Furthermore, an immature DPSC (iDPSC) population was obtained from SHED via explant method. These cells expressed embryonic stem cell markers and showed dense engraftment. ${ }^{17}$ Although both methods yield similar cell populations, probably, the advantage of employing enzyme is that it releases all different types of cells present in the DP tissue. ${ }^{15}$

Primary culture of DPSCs grows slowly, ${ }^{15}$ our cells also took longer time to grow in culture. We also performed enzymatic digestion by treating minced DP tissue with $3 \mathrm{mg} / \mathrm{mL}$ collagenase type 1and dispase type II. However, it gave low cell yield which remained unable to grow. In our experiments, the undigested tissue fragments seemed to be the sole source of cells in culture (data not shown). Further, the use of undigested tissue to obtain dental stem cells has also been mentioned in literature. ${ }^{18}$ Cryopreservation protocol if not followed properly may result in reduced viability of stored cells. The protocol we used was effective for maintaining more than $90 \%$ viability of dental MSCs.

Extracted teeth, considered as clinical waste, offer a promising source of autologous cells. These cells can potentially be used for regeneration of musculoskeletal ${ }^{19}$ chondrocytes, adipocytes, cornea, hair follicle, and endothelial cells. ${ }^{20,21}$ Previous studies demonstrated the transdifferentiation of human dental pulp cells into neuron-like cells, ${ }^{22}$ oligoprogenitors, ${ }^{23}$ cardiomyocytes, ${ }^{24}$ and insulin producing cells. ${ }^{25}$ Above mentioned studies provide evidence in favor of regenerative potential of dental pulp MSCs.

Considering the most accessible and feasible cell source, the usefulness of dental pulp stem cells or dental cells in generating iPSCs has also been documented in literature. SHED, SCAP, ${ }^{26}$ and DPSCS can easily be reprogrammed into iPSCs at relatively higher rates. ${ }^{27}$ Very recently, human dental stem cell derived transgene-free iPSCs were successfully used to generate functional neurons, exhibiting sodium and potassium currents, action potential, or spontaneous excitatory postsynaptic potential. ${ }^{18}$

We report a protocol for the extirpation of dental pulp tissue, in-vitro explant culture and propagation of dental pulp MSCs from permanent and deciduous human teeth. MSCs are comprised of heterogeneous population thus it is important to characterize them for the presence of stem cell sub-populations. Therefore, we plan to characterize these cells using classical MSCs markers and their regeneration potential in-vitro. We believe, the major benefits from the protocol that it could provide a reliable source of stem cells to be used in regeneration of damaged or diseased tissue or organs, generation of patient specific stem cells and iPSCs banking.

Grant Support \& Financial Disclosures: Higher Education Commission Pakistan. Department of Surgery, Aga Khan University, Karachi, Pakistan.

\section{REFERENCES}

1. Ledesma-Martinez E, Mendoza-Nunez VM, SantiagoOsorio E. Mesenchymal Stem Cells Derived from Dental Pulp: A Review. Stem Cells Int. 2016;2016:4709572. doi: 10.1155/2016/4709572.

2. da Silva Meirelles L, Chagastelles PC, Nardi NB. Mesenchymal stem cells reside in virtually all post-natal organs and tissues. J Cell Sci. 2006;119(Pt 11):2204-2213 doi: $10.1242 /$ jcs.02932.

3. Friedenstein AJ, Petrakova KV, Kurolesova AI, Frolova GP. Heterotopic of bone marrow. Analysis of precursor cells for osteogenic and hematopoietic tissues. Transplantation. 1968;6(2):230-247.

4. Perez-Silos V, Camacho-Morales A, Fuentes-Mera L. Mesenchymal Stem Cells Subpopulations: Application for Orthopedic Regenerative Medicine. Stem Cells Int. 2016;2016:3187491. doi: 10.1155/2016/3187491. 
5. Gronthos S, Mankani M, Brahim J, Robey PG, Shi S. Postnatal human dental pulp stem cells (DPSCs) in vitro and in vivo. Proc Natl Acad Sci USA. 2000;97(25):1362513630. doi: 10.1073/pnas.240309797.

6. Huang GT, Yamaza T, Shea LD, Djouad F, Kuhn NZ, Tuan RS, et al. Stem/progenitor cell-mediated de novo regeneration of dental pulp with newly deposited continuous layer of dentin in an in vivo model. Tissue Eng Part A. 2010;16(2):605-615. doi: 10.1089/ten.TEA.2009.0518.

7. Miura M, Gronthos S, Zhao M, Lu B, Fisher LW, Robey PG, et al. SHED: stem cells from human exfoliated deciduous teeth. Proc Natl Acad Sci U S A. 2003;100(10):5807-5812. doi: 10.1073/pnas.0937635100.

8. Pierdomenico L, Bonsi L, Calvitti M, Rondelli D, Arpinati M, Chirumbolo G, et al. Multipotent mesenchymal stem cells with immunosuppressive activity can be easily isolated from dental pulp. Transplantation. 2005;80(6):836-842. doi: 10.1097/01.tp.0000173794.72151.88.

9. Nakashima M, Iohara K, Murakami M, Nakumura H, Sato $Y$, Ariji $Y$, et al. Pulp regeneration by transplantation of dental pulp stem cells in pulpitis: A pilot clinical study. Stem Cell Res Ther. 2017;8(1):61. doi: 10.1186/s13287-017-0506-5.

10. Strober W. Trypan Blue Exclusion Test of Cell Viability. Curr Protoc Immunol. 2015;111:A3.b.1-3. doi: 10.1002/0471142735.ima03bs111.

11. Hilkens P, Gervois P, Fanton Y, Vanomelingen J, Martens W, Struys T, et al. Effect of isolation methodology on stem cell properties and multilineage differentiation potential of human dental pulp stem cells. Cell Tissue Res. 2013;353(1):65-78. doi: 10.1007/s00441-013-1630-x.

12. Bakopoulou A, About I. Stem Cells of Dental Origin: Current Research Trends and Key Milestones towards Clinical Application. Stem Cells Int. 2016;2016:4209891. doi: 10.1155/2016/4209891.

13. Jang JH, Lee HW, Cho KM, Shin HW, Kang MK, Park SH, et al. In vitro characterization of human dental pulp stem cells isolated by three different methods. Restor Dent Endod. 2016;41(4):283-295. doi: 10.5395/rde.2016.41.4.283.

14. Perry BC, Zhou D, Wu X, Yang FC, Byers MA, Chu TM, et al. Collection, cryopreservation, and characterization of human dental pulp-derived mesenchymal stem cells for banking and clinical use. Tissue Eng Part C Methods. 2008;14(2):149-156. doi: 10.1089/ten.tec.2008.0031.

15. Huang GT, Sonoyama $W$, Chen J, Park SH. In vitro characterization of human dental pulp cells: various isolation methods and culturing environments. Cell Tissue Res. 2006;324(2):225-236. doi: 10.1007/s00441-005-0117-9.

16. Couble ML, Farges JC, Bleicher F, Perrat-Mabillon B, Boudeulle M, Magloire H. Odontoblast differentiation of human dental pulp cells in explant cultures. Calcif Tissue Int. 2000;66(2):129-138.

17. Kerkis I, Kerkis A, Dozortsev D, Stukart-Parsons GC, Gomes Massironi SM, Pereira LV, et al. Isolation and characterization of a population of immature dental pulp stem cells expressing OCT-4 and other embryonic stem cell markers. Cells Tissues Organs. 2006;184(3-4):105-116. doi: 10.1159/000099617.

18. El Ayachi I, Zhang J, Zou XY, Li D, Yu Z, Wei W, et al. Human dental stem cell derived transgene-free iPSCs generate functional neurons via embryoid body-mediated and direct induction methods. J Tissue Eng Regen Med. 2018;12(4):e1836-e1851. doi: 10.1002/term.2615.

19. Tatullo M, Marrelli M, Shakesheff KM, White LJ. Dental pulp stem cells: Function, isolation and applications in regenerative medicine. J Tissue Eng Regen Med. 2015;9(11):1205-1216. doi: 10.1002/term.1899.
20. Kawashima N. Characterisation of dental pulp stem cells: A new horizon for tissue regeneration? Arch Oral Biol. 2012;57(11):1439-1458. doi: 10.1016/j.archoralbio.2012.08.010.

21. Nuti N, Corallo C, Chan BM, Ferrari M, Gerami-Naini B. Multipotent Differentiation of Human Dental Pulp Stem Cells: a Literature Review. Stem Cell Rev. 2016;12(5):511523. doi: $10.1007 / \mathrm{s} 12015-016-9661-9$.

22. Chang CC, Chang KC, Tsai SJ, Chang HH, Lin CP. Neurogenic differentiation of dental pulp stem cells to neuron-like cells in dopaminergic and motor neuronal inductive media. J Formos Med Assoc. 2014;113(12):956-965. doi: 10.1016/j.jfma.2014.09.003.

23. Moayeri A, Nazm Bojnordi M, Haratizadeh S, EsmaeilnejadMoghadam A, Alizadeh R, Ghasemi Hamidabadi H. Transdifferentiation of Human Dental Pulp Stem Cells Into Oligoprogenitor Cells. Basic Clin Neurosci. 2017;8(5):387-394 doi: 10.18869/nirp.bcn.8.5.387.

24. Sung IY, Son HN, Ullah I, Bharti D, Park JM, Cho YC, et al. Cardiomyogenic Differentiation of Human Dental Follicle-derived Stem Cells by Suberoylanilide Hydroxamic Acid and Their In Vivo Homing Property. Int J Med Sci. 2016;13(11):841-852. doi: 10.7150/ijms.16573.

25. Carnevale G, Riccio M, Pisciotta A, Beretti F, Maraldi T, Zvatti M, et al. In vitro differentiation into insulin-producing beta-cells of stem cells isolated from human amniotic fluid and dental pulp. Dig Liver Dis. 2013;45(8):669-676. doi: 10.1016/j.dld.2013.02.007.

26. Zou XY, Yang HY, Yu Z, Tan XB, Yan X, Huang GT. Establishment of transgene-free induced pluripotent stem cells reprogrammed from human stem cells of apical papilla for neural differentiation. Stem Cell Res Ther. 2012;3(5):43. doi: $10.1186 /$ scrt134

27. Yan X, Qin H, Qu C, Tuan RS, Shi S, Huang GT. iPS cells reprogrammed from human mesenchymal-like stem/ progenitor cells of dental tissue origin. Stem Cells Dev. 2010;19(4):469-480. doi: 10.1089/scd.2009.0314.

\section{Author`s Contribution:}

SN contributed in sample collection and transportation to research lab, designed and performed the experiments, literature search, statistical analysis, manuscript writing and editing of manuscript.

FRK conceived the idea, designed study, obtained specimens, wrote manuscript and reviewed the manuscript.

RRZ critically reviewed the manuscript.

SSL carried out ordering, conducted pilot experiment, literature search.

MSK carried out ordering, conducted pilot experiment, and literature search.

NM participated in study design, interpreted data and reviewed manuscript.

TA supervised the project, wrote manuscript and critically reviewed the manuscript.

All authors have approved the final version of the manuscript and disclose no conflict of interest. 